\title{
Alleviating Water Scarcity in the Central Rift Valley Lakes through an Inter-Basin Water Transfer, Ethiopia
}

\author{
Belete Berhanu, Ethiopia Bisrat \\ School of Civil and Environmental Engineering, Institute of Technology, Addis Ababa, Ethiopia \\ Email: belete.berhanu@aait.edu.et
}

How to cite this paper: Berhanu, B. and Bisrat, E. (2020) Alleviating Water Scarcity in the Central Rift Valley Lakes through an Inter-Basin Water Transfer, Ethiopia. Natural Resources, 11, 554-568.

https://doi.org/10.4236/nr.2020.1112033

Received: November 11, 2020

Accepted: December 15, 2020

Published: December 18, 2020

Copyright (อ 2020 by author(s) and Scientific Research Publishing Inc. This work is licensed under the Creative Commons Attribution International License (CC BY 4.0).

http://creativecommons.org/licenses/by/4.0/

\section{(c) (i) Open Access}

\begin{abstract}
Demand for fresh water, as one of the major natural resources, is increasing rapidly with increasing development and environmental degradation. The continued abstraction of water from Lake Ziway and its main feeder rivers Meki and Katar for irrigation indicates that the water demand may soon exceed the supply. To illustrate disparities in spatial distribution of water resources, the Upper Awash sub-basin, which shares a water-divide with the CRVL sub-basin, has large flow volumes particularly in the rainy season and suffers with seasonal flooding. The rationale behind regaining the water in CRVL relies on this non-uniform spatial distribution of fresh water, calling for a balance between water surplus and deficit regions. For this reason, Inter Basin Water Transfer (IBWT) is suggested as a viable option to augment utilizable water resources of the Upper Awash sub-basin to reduce the significant pressure on the water supply of the rapidly developing urban and irrigation areas in the CRVL sub-basin. A water evaluation and planning (WEAP) model was used to quantify the amount of surplus water in the donor basin, when examining the hydrological dynamics of the basins. Furthermore, optimal flow diversion scenarios were generated by maintaining two baseline scenario constraints. The estimated surplus water in the rainy season is expected to contribute 18 million cubic meters $(\mathrm{mcm}), 88 \mathrm{mcm}$ and $192 \mathrm{mcm}$ in months June, July and August respectively under average conditions. The optimal amount of diverted water could potentially stabilize the environmental degradation of Lake Ziway and Lake Abijata by compensating for development-driven abstraction and surface water evaporation respectively.
\end{abstract}

\section{Keywords}

Inter Basin Water Transfer, WEAP, Lake Ziway, Upper Awash Sub-Basin, CRVL 


\section{Introduction}

Ethiopian water bodies, particularly the Central Rift valley Lakes (CRVL), have been faced with changes like water level reduction, land degradation, and overutilization [1]. In the last three to four decades, many small-holder farmers as well as large agribusinesses have been increasingly abstracting large amount of water for irrigation from Lake Ziway and its feeder rivers Meki and Katar [2]. Lake Ziway is the major fresh water source of water for Lake Abijata that is interconnected through Bulbula River. Numerous studies characterize the water resource system as an overexploited and environmentally degraded sub-basin, having low water quality and high sensitivity to climatic variation, that is relied upon by 7.73 million inhabitants for their livelihood [3]-[8]. According to [3] [9] [10], decline in water level of Lake Abijata has translated into a reduction of $35 \%$ - $60 \%$ of the surface area recorded in 1974, which resulted in loss of population of international migrant birds and decline of water-related economic activities in the area.

In contrast, the Upper Awash sub-basin, which shares a water-divide with the CRVL sub-basin, has large flow volumes particularly in the rainy season and suffers with seasonal flooding. It also lacks significant a storage facility to store the high seasonal water within the basin itself, since Koka Reservoir, which was constructed in 1960 was the only reservoir located in the sub-basin. Due to its long service year and sedimentation load, Koka Reservoir has lost about $40 \%$ of its installed storage capacity and currently stores only about 1 billion cubic meters $(\mathrm{bcm})$, which is much lower than the annual surface water production of the Upper Awash sub-basin [11].

This skewed distribution of water availability, which occurs as a consequence of regional variation in precipitation and availability of water storage, suggests an inter-basin water transfer from the Upper Awash sub-basin to the Central Rift valley lake sub-basin through the use of a naturally existing storage mechanism i.e. Lake Ziway. In many parts of the world, water transfer has been a complementary water management strategy for promoting socioeconomic development and environmental protection in water-scarce regions. In the twentieth century, the rapid growth of human population, economic activities and human settlement in water-scarce regions, advances in science and technology, political will and availability of resources led to the development of many water transfer projects. To reduce water shortage and uneven distribution, more than 160 water transfer projects have been carried out worldwide until 2015 [12]. The global inter-basin water transfer increased from 22 to 56, from 56 to 257 and from 257 to $364 \mathrm{~km}^{3} /$ year during the periods $1900-1940,1940-1980$ and $1980-1986$, respectively, and is estimated to increase to $760-1240 \mathrm{~km}^{3} /$ year by 2020 [13].

In addition to identifying the donor (surplus) basin and recipient (deficit) basin, quantifying the optimal amount of surplus water in the basin is important. This paper develops a conceptual Water Evaluation and Planning (WEAP) model to represent the main water supply and demand features of the sub-basins 
to estimate the optimal seasonal surplus water from the Upper Awash sub-basin that can potentially be transferred.

\section{Material and Methods}

\subsection{Study Area Description}

The Upper Awash sub basin (donor basin) and CRVL sub-basin (receiving basin) are the two upstream sub basins of the two rift valley based basins Awash Basin and Rift Valley Lakes basin respectively. Geographically, they are located in range of $37^{\circ} 56^{\prime} \mathrm{E}-39^{\circ} 26.45^{\prime} \mathrm{E}$ and $7^{\circ} 1^{\prime} \mathrm{N}-9^{\circ} 19.25^{\prime} \mathrm{N}$ (Figure 1 ). They share the Ziquala mountain belt as common boundary, which divides the flow direction of the two basins in opposite directions. The flow in the Upper Awash Basin is in the north east direction, whereas in the CRVL sub-basin it is in the South West direction. Because of the orographic effect of the mountains, the Upper Awash sub-basin receives higher rainfall than the CRVL sub-basin.

The CRVL sub-basin falls in the R3-A3 rainfall regime characterized by bi-modal, 4 - 5 rainfall months, and medium annual rainfall, which ranges from 707 - 1166 $\mathrm{mm}$ /annum. The sub basin has two principal rivers, Meki and Katar Rivers that originate from the Gurage Mountains in the west and the Arsi Mountains in the east respectively [8] and feeding Lake Ziway as major sources of fresh water in the sub basin. The mean annual flow of the two Rivers, Meki and Katar are 283 $\mathrm{mcm}$ and $426 \mathrm{mcm}$ respectively.

The annual water volume in the Upper Awash Basin ranges from $296 \mathrm{mcm}$ to $4443 \mathrm{mcm}$ and the average annual is estimated to be $1366 \mathrm{mcm}$. The Upper Awash sub-basin gets $84 \%$ of its mean annual water flows between June and

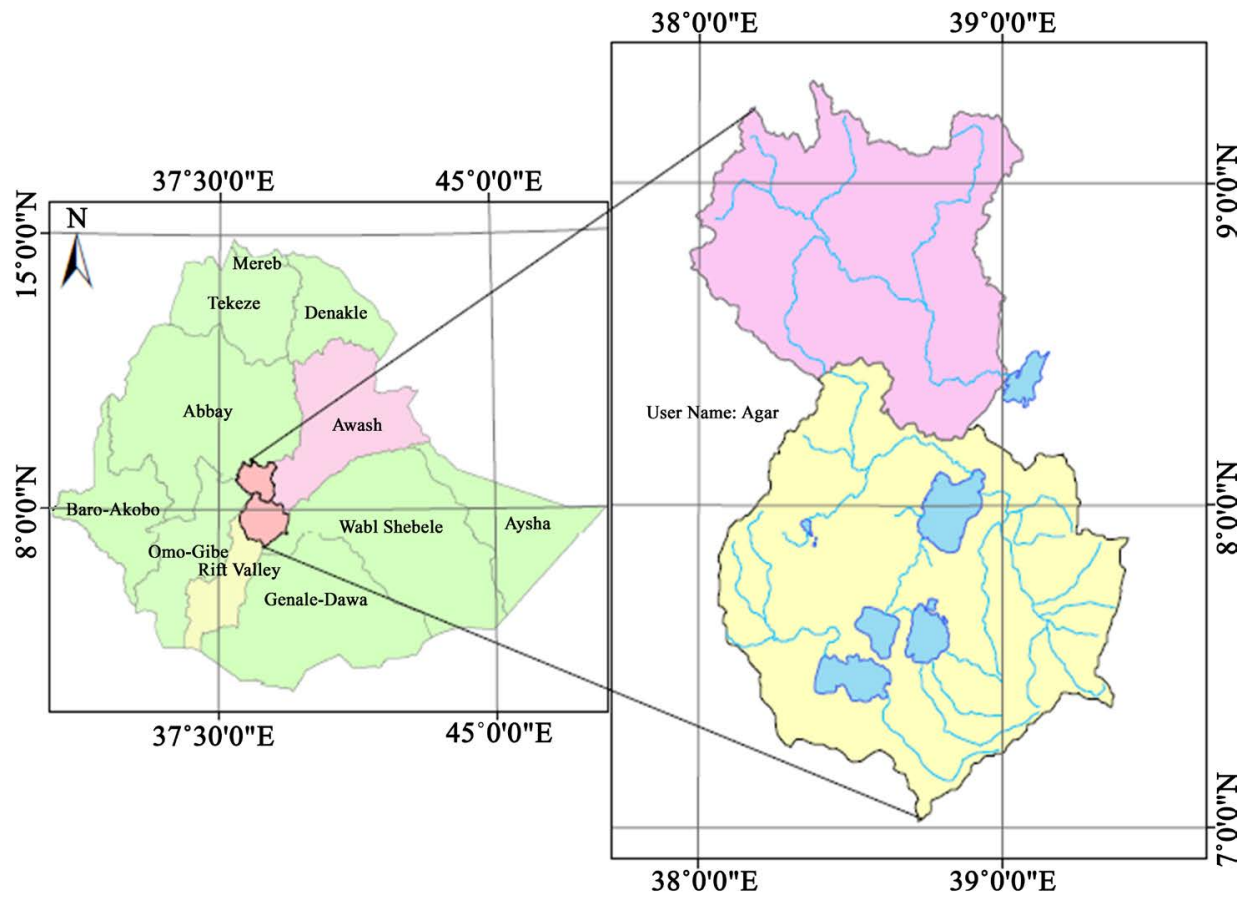

Figure 1. Location map of Upper Awash and CRVL sub-basins within Ethiopia. 
September, where intense rainfall in the highlands of the sub basin causes flooding of settlements close to the river course [14]. This is attributed to the fact that any incoming water above the capacity of the Koka Reservoir spills and causes damage to downstream developments and settlements. Harnessing water of the Upper Awash sub-basin by interlinking the rivers of both basins thus creates an storage utilization mechanism which makes IBWT a rational option to overcome problems caused due to mismatch between supply, storage and demand.

\subsection{The Upper Awash-CRVL WEAP System Model}

Since comparison between the water balance of the two river basins is the main rationale for decision making, this study used the Water Evaluation and Planning (WEAP) model to examine hydrologic dynamics in the Upper-Awash River and CRVL sub-basins. The WEAP model is one of the most powerful tools used to evaluate the existing and planned water resource developments in a watershed [15]. In the WEAP model, natural hydrologic processes as well as anthropogenic activities are simulated by placing demand-side issues on par with supply-side dynamics. Supply is modeled by reproducing both its managed components (stream flow diversions, groundwater pumping, reservoirs, and water transfers) and its natural components (evapotranspiration demands, runoff, and base flow) [16]. Similarly, the demand-side addressed all potential water uses that include rain-fed and irrigated agriculture, domestic, industrial and in-stream flow requirements. Within WEAP, it is necessary to set the spatial scope of the analysis by defining the boundaries of the catchment. Within these boundaries there are smaller rivers and streams that flow into the main river of interest. Because these tributaries determine the distribution of water throughout the basin, it is also necessary to divide the study area into sub-basins such that we can characterize this spatial variability of river flows. The Upper Awash River basin extends from Awash-Kuntre up to Koka Reservoir which is considered as the flow generator for diversion into the CRVL sub-basin; the CRVL sub basin contributes to the downstream side (the receiving end) of the simulation. This basin includes the Meki and Katar sub-basins contributing to Lake Ziway.

\subsection{Supply-Side Model Configuration (Hydrological Model)}

Four methods are available to simulate watershed hydrological processes in WEAP which hinges on the level of complexity desired for representing the catchment process and data availability [17]. The Soil Moisture method was selected to simulate the hydrology of the basins and estimate the available water in different elements of the hydrological cycle. This method was adopted for simulating the hydrology in the two-bucket model as precipitation, temperature, relative humidity and wind parameters were added into the model. This method allows for the characterization of land use and soil type impacts to these processes. In the upper soil layer, it simulates evapotranspiration considering rainfall and irrigation on agricultural and non-agricultural land, runoff and shallow inter- 
flow, and changes in soil moisture. Base flow routing to the river and soil moisture changes is simulated in the lower soil layer [17]. Each of the catchments in the model setup contains climate data that are used as drivers for the routines that estimate the hydrological response. These data include monthly time series of precipitation $(\mathrm{mm})$, average observed temperature ( $\operatorname{deg} \mathrm{C})$, relative humidity (\%) and wind speed $(\mathrm{m} / \mathrm{s})$. The $4 \mathrm{~km}$-grid CHRIPS rainfall product [18] was converted to a single point represented by the centroid of each catchment and the associated temperature data was obtained by selecting an observed data with a similar elevation (Figure 2(a)). This study adopted a monthly time step where observations between 1981 and 2016 were used. Configuration of the Upper Awash and CRVL sub basin are represented together in a single model configuration (Figure 2(b)).

\subsection{Demand-Side Model Configuration}

An important requirement for establishing the system includes the specification of the supply and demand data where the latter accounts for the different water use sectors. These water use sectors include domestic, industrial, rain-fed and irrigated agriculture and in-stream flow requirements. The common procedure followed for estimating demands for domestic and livestock is using population data from the Central statistics Authority (CSA) and annual water use rate based on urban, rural and livestock groups (Table 1). The agricultural water demand is computed based on area of irrigated and rain-fed cultivation multiplied by the annual use rate of the major crop type and its monthly water demand distribution

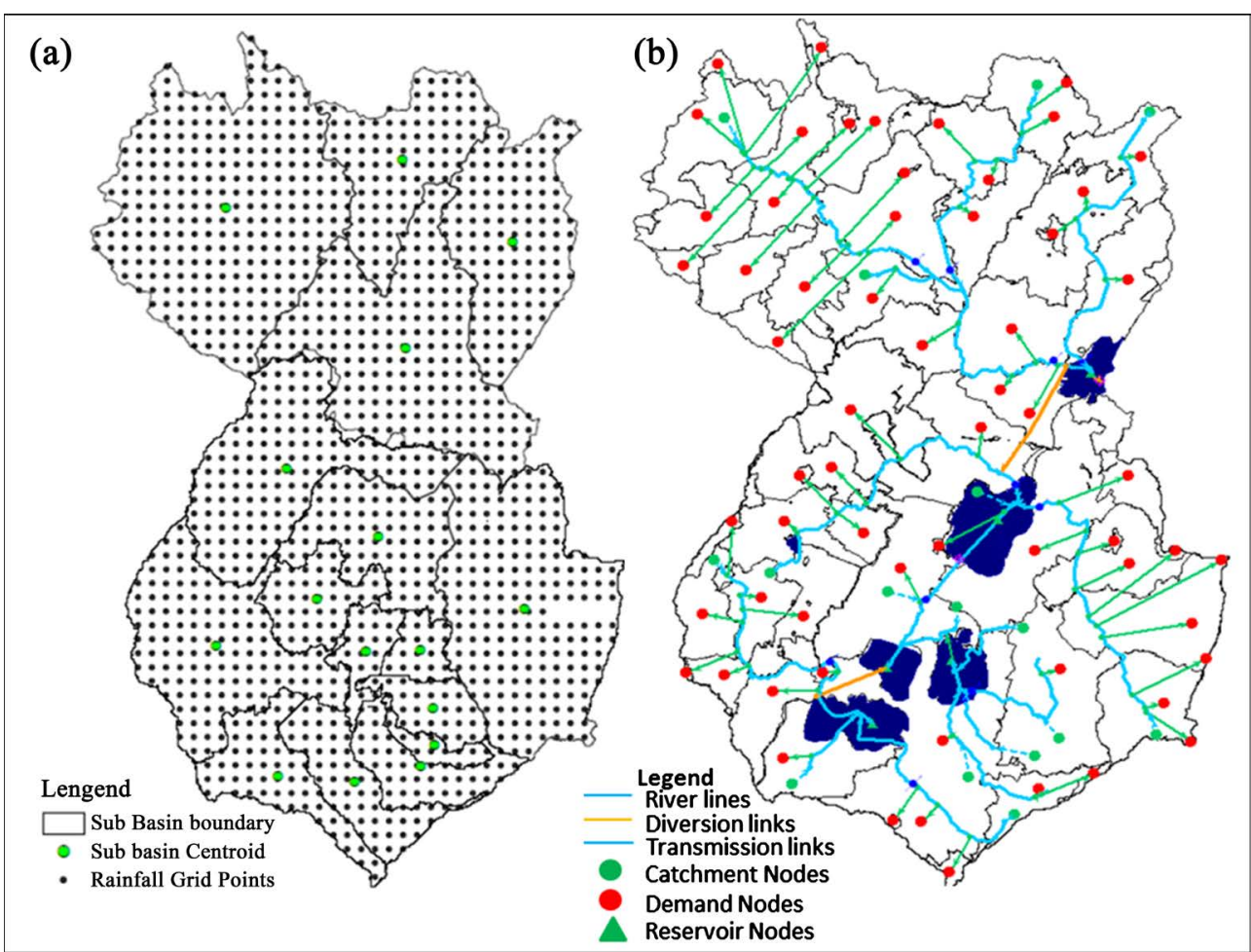

Figure 2. (a) Distributed climate grids with meteorology observatory stations, (b) WEAP schematic. 
Table 1. Annual water use rate for the different sectors under municipal water consumption.

\begin{tabular}{lccccccccc}
\hline & Urban Pop & Rural Pop & Cattle & Equines & Camel & Sheep & Goat & Poultry & Beehive \\
\hline Annual water use rate $\left(\mathrm{m}^{3} / \mathrm{head}\right)$ & 7.3 & 5.475 & 10.95 & 8.2125 & 10.95 & 1.825 & 1.825 & 0.064 & 4.015 \\
\hline
\end{tabular}

Table 2. Agricultural monthly water use variation adopted by catchment.

\begin{tabular}{|c|c|c|c|c|c|c|c|c|c|c|c|c|}
\hline \multirow{2}{*}{ Catchment } & \multicolumn{12}{|c|}{ Monthly variation of irrigation demand (percent) } \\
\hline & Jan & Feb & Mar & Apr & May & June & July & Aug & Sept & Oct & Nov & Dec \\
\hline Main Awash & 11.8 & 8.5 & 6.2 & 9.8 & 11.9 & 10.3 & 0.036 & 0.044 & 0.76 & 11.8 & 15.3 & 12.2 \\
\hline Melkakuntre & 17.6 & 15.2 & 18.0 & 10.3 & 7.5 & 1.3 & 0 & 0 & 0.5 & 6.1 & 10.4 & 12.8 \\
\hline Akaki & 21.7 & 12.2 & 14.1 & 10.1 & 8.1 & 0.2 & 0 & 0 & 0.1 & 7.5 & 10.4 & 15.6 \\
\hline Mojo & 14.5 & 12.9 & 13.8 & 12.5 & 14.9 & 4.9 & 0 & 0 & 1.4 & 4.1 & 9.6 & 11.1 \\
\hline Meki & 11.8 & 8.5 & 6.2 & 9.8 & 11.9 & 10.3 & 0.036 & 0.044 & 0.76 & 11.8 & 15.3 & 12.2 \\
\hline Katar & 5.1 & 7.2 & 10.2 & 8.3 & 6.1 & 7.2 & 0.02 & 0.02 & 12.5 & 19.3 & 13.4 & 10.4 \\
\hline
\end{tabular}

percentages (Table 2).

\subsection{Reservoir Configuration}

The storage systems in the sub-basins are configured using built-in reservoir nodes in the WEAP model that represent controlled release of stored water. The study area comprises of five major water storage systems as artificial reservoirs (Koka Dam) and interconnected natural lake systems (Lakes Ziway, Abijata, Langano and Shalla). WEAP uses generic reservoir objects that divide storage into four zones, or pools. These are, from top to bottom: the flood-control zone, conservation zone, buffer zone and inactive zone. The conservation and buffer pools together constitute the reservoir's active storage [16]. The size of each of these pools can change throughout the year according to regulatory guidelines, such as volume-elevation rule curves (Figure 3 ).

\subsection{Calibration and Validation of the WEAP Model}

The WEAP model was calibrated to historical stream flows using manual methods. Calibration was achieved by estimating the historic pattern of water demand and simulating the resultant flows. This involved changing land-use parameters, altering demand priorities, modifying the operating rules of flow requirements downstream of dams to improve the fit between simulated and observed flows. Three most sensitive land-use parameters were adjusted to achieve calibration to stream flow: Soil Water Capacity (SWC), Runoff Resistance Factor (RRF) and Deep Conductivity (DC). Model simulations are most sensitive to RRF, thus initial calibrations were focused on this parameter. Further refinements for base flow, shape of hydrograph and timing of peak flows were adjusted using the remaining parameters. To check the accuracy of the model, validation was also done with different time periods of observed and simulated data using the values of the parameters adjusted during calibration. 


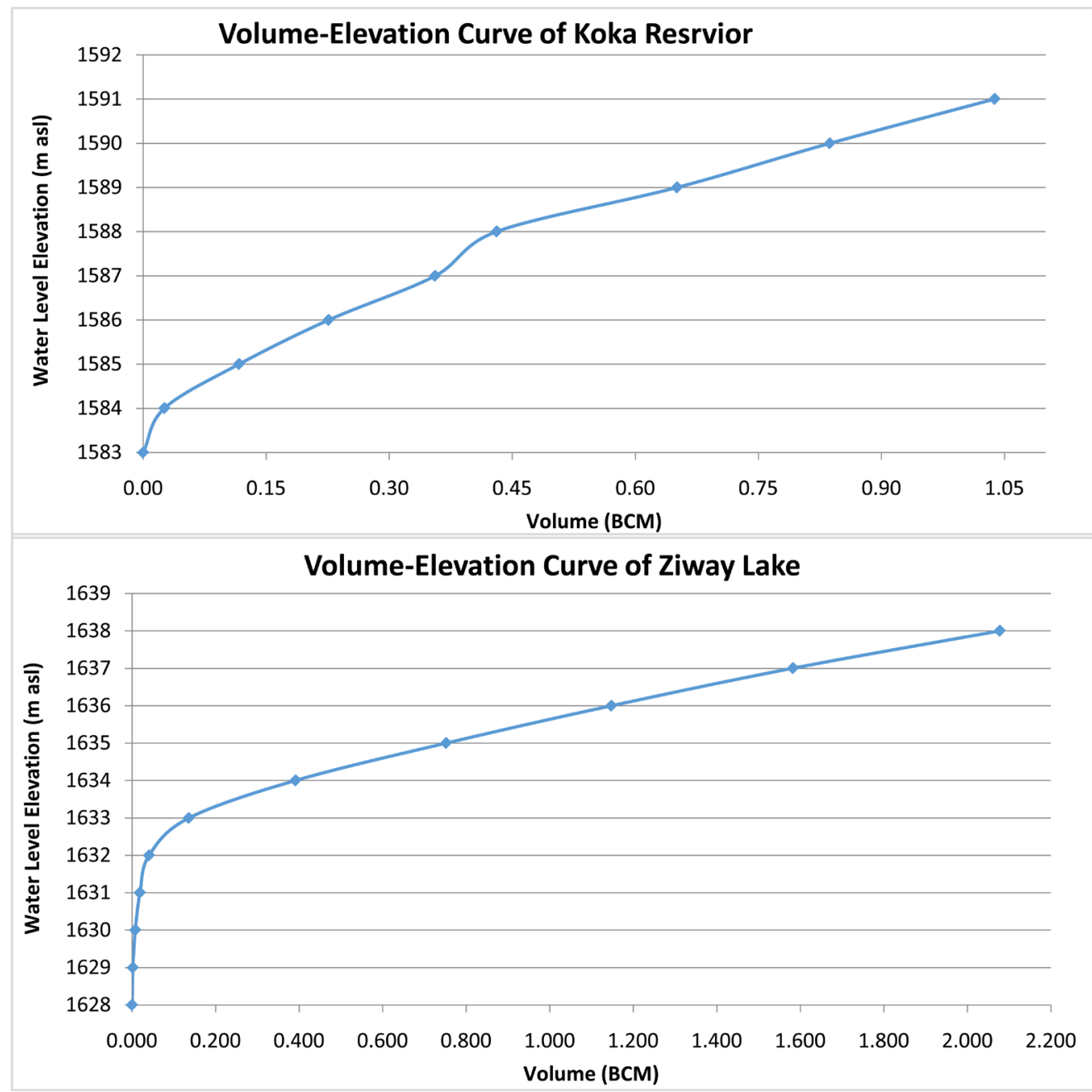

Figure 3. Volume-elevation curves of Koka reservoir and Lake Ziway.

The Nash-Sutcliffe Efficiency (NSE), coefficient of determination $\left(\mathrm{R}^{2}\right)$ and percent bias (PBIAS) were used to evaluate how well the modeled stream flow matched the observed data.

\section{Results}

\subsection{Model Calibration}

Data from stream flow-gauging stations within the basin operated by the Ministry of Water Resources, Irrigation and Energy (MoWIE) of Ethiopia were used for calibrating the hydrology of the basin. The results of this calibration are summarized in Table 3 and corresponding figures (Figure 4). Results close to 1 $(>0.8)$ for both $\mathrm{R}^{2}$ and NSE along with values close to zero for PBIAS (in the range of \pm 20 ) confirm that the model is well calibrated in terms of achieving acceptable values of statistical performance measures.

\subsection{Model Validation}

Prior to estimating the magnitude of flow that can potentially be diverted from 
Table 3. Statistics for observed vs simulated flow at selected gauge stations for model calibration.

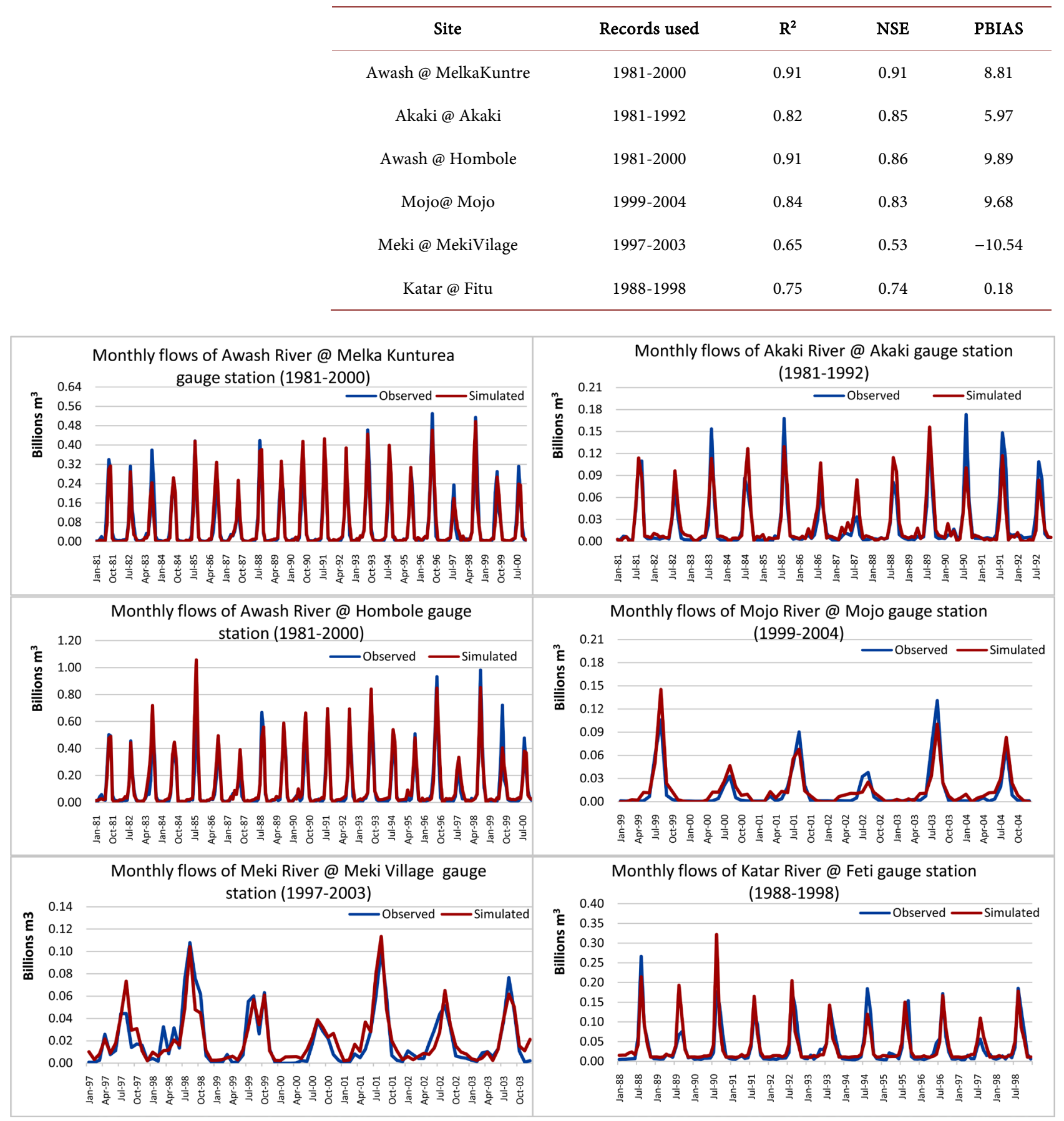

Figure 4. Calibration results of stations in the Upper Awash and CRVL sub basins.

Awash River to Lake Ziway, the accuracy of the model was evaluated. This was done by comparing observed and simulated flow for the validation period. Validation results for simulated and observed flow at these stations also verify the model accuracy in terms of achieving acceptable statistical measures (Table 4 and Figure 5). 
Table 4. Statistics of observed and simulated values of WEAP model validation.

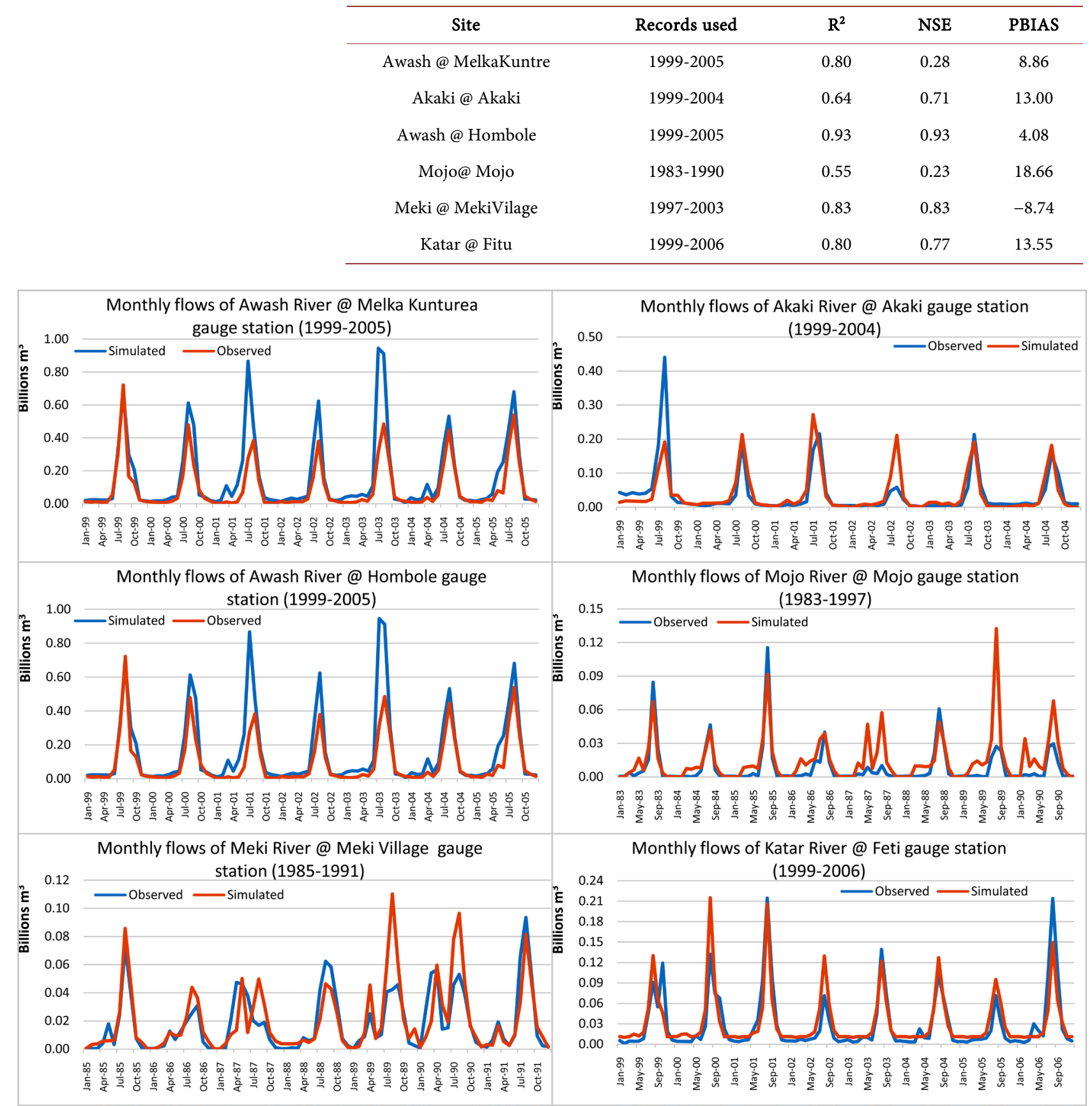

Figure 5. Validation results of stations in the upper awash and CRVL sub basins.

\subsection{Base Case: Quantifying the Amount of Surplus Water in the Basin}

Once the model accuracy was validated, the base line scenario was set by selecting the river flow at different target locations in order to analyze the flow magnitude before diversion. These locations include: Awash River below Hombole gauge (at diversion location), Mojo River at Koka Junction, inflow at Koka, Meki River at Ziway junction and Katar River at Ziway junction. Awash at Hombole, 
and Mojo at Koka junction have mean annual flows of $1348 \mathrm{mcm}$ and $190 \mathrm{mcm}$ respectively and the sum of the two main tributaries at Koka inflow is 1538 $\mathrm{mcm}$. This indicates that there is a surplus of $500 \mathrm{mcm}$ water flowing into the Koka Reservoir which has a capacity of 1038 million cubic meters. Furthermore, the annual time series analysis (1981-2016) of Koka Reservoir inflow ranges from $851-2500 \mathrm{mcm}$, where inflow exceeds the current storage capacity of Koka Reservoir $95 \%$ of the time (Figure 6).

Similarly, the two major rivers: Meki and Katar together with small ungauged streams contribute a total of $1038 \mathrm{mcm}$, which is much lower than the storage capacity of Ziway Lake, $1583 \mathrm{mcm}$. These results establish that the surplus water available at the Upper Awash River can be accommodated in the Ziway Lake to overcome the deficit.

\subsection{Flow Diversion Scenarios}

The diversion link in the WEAP model was added to divert water from the main Awash River at Hombole to Meki River (Figure 7). The location was strategically selected based on its suitable topology which descends continuously down to Meki River where it would potentially divert the water via an earth canal using gravity only. In this modeling scenario, the optimal amount of water that can be diverted was computed with two control conditions at both upstream and downstream

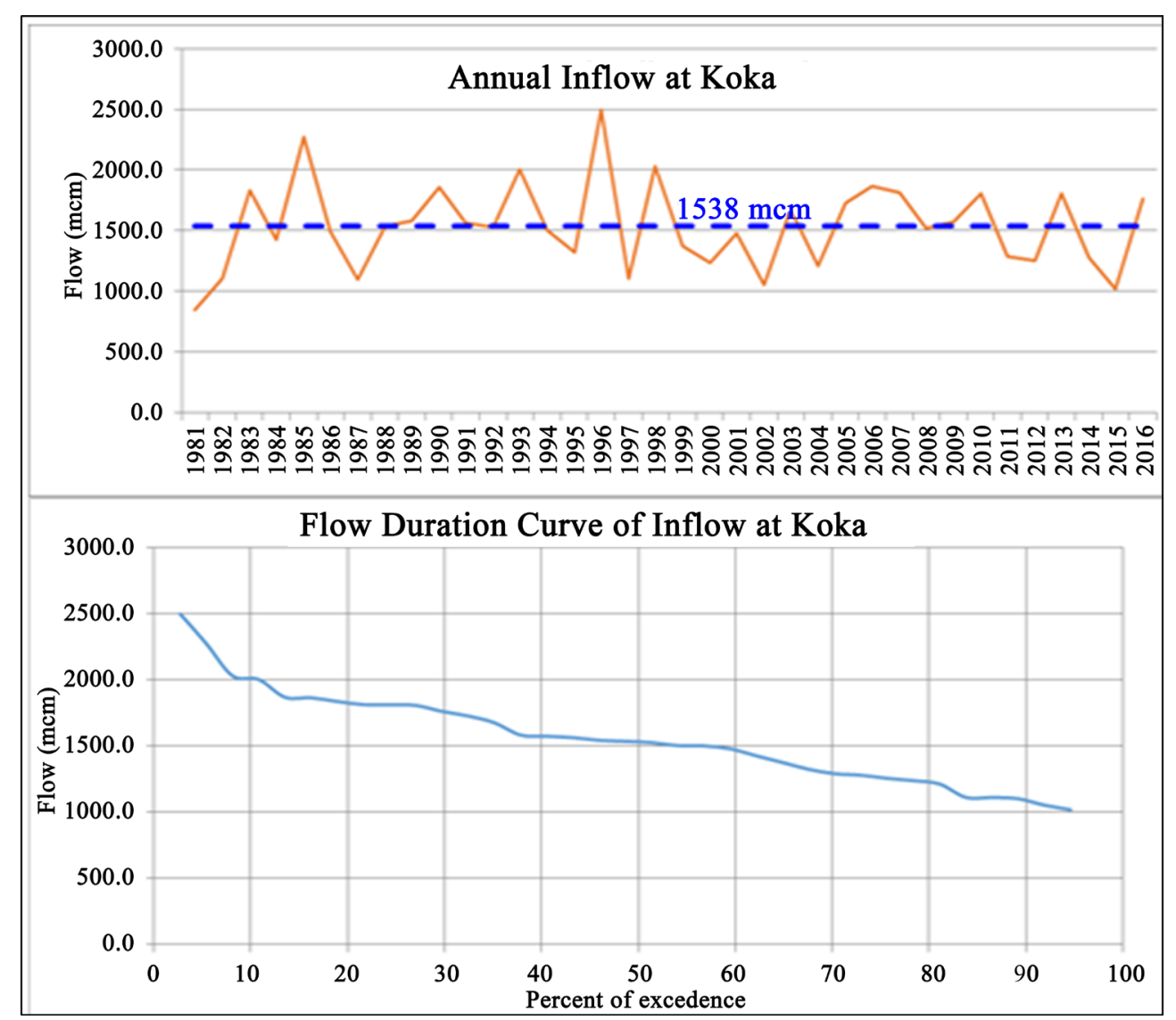

Figure 6. Annual time series flow and flow duration curve of Awash River at Koka inlet. 


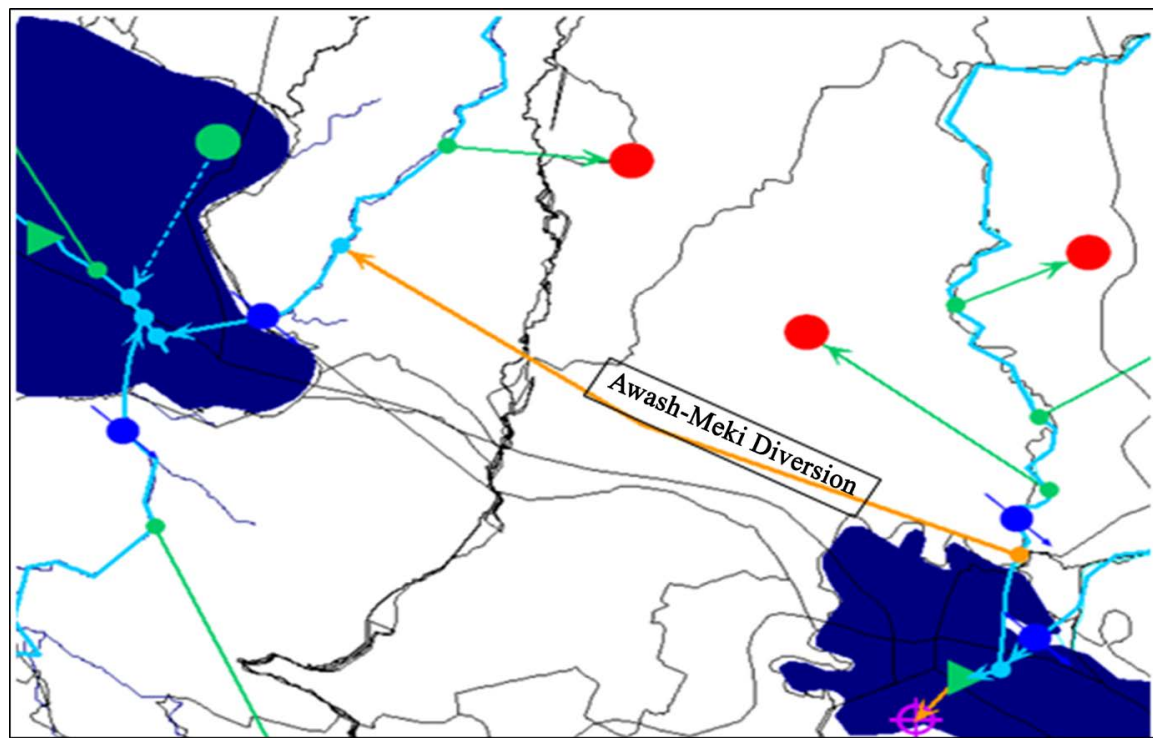

Figure 7. Proposed water transfer corridor with model diversion link.

locations. Upstream of the diversion, supply delivered for sectoral water use is kept constant by assigning the highest priority to upstream demand nodes; and at downstream, the Koka Reservoir is kept full at the end of the rainy season (September). To guarantee constant conditions for upstream demand during dry months, percentage of diverted water at Awash River diversion node was set to zero. In contrast, for the three months during the rainy season: June, July and August, the percentage fraction was established to only divert the surplus portion of the flow. The diversion fraction for the wet period was adjusted in such a way that the assigned constraints were fully maintained.

An optimal amount of $301 \mathrm{mcm}$ flows was computed to be diverted from Awash River to Ziway Lake through Meki River with 35\% diversion rate in June, July and August and only excess flow in September. With the estimated flow diversion, the four months contribute $18 \mathrm{mcm}, 88 \mathrm{mcm}, 192 \mathrm{mcm}$ and $3 \mathrm{mcm}$ respectively, where both upstream and downstream constraints maintained the baseline scenario, i.e. water delivered to upstream demand nodes and the Volume of water at Koka Reservoir were kept constant (Table 5).

When considering the inter-annual variability of the volume of water that could potentially be diverted, values range from $204 \mathrm{mcm}$ to $553 \mathrm{mcm}$. This is in line with the annual rainfall variation over the study period. In addition to quantifying the volume of surplus water, it is equally important to estimate the maximum discharge that could be diverted in order to design the diversion canal. A discharge as high as 137 cubic meters per second (cms) is thus estimated which has significant variability across months and years. In June, the maximum flow is estimated as $19 \mathrm{cms}$ with $7 \mathrm{cms}$ average flow; in July, $66 \mathrm{cms}$ and $32 \mathrm{cms}$ computed as maximum and average flow respectively; and in August, the maximum and average diverted flow is estimated at $137 \mathrm{cms}$ and 48 cms respectively. 
Table 5. The volume of water for assigned constraints at base and diversion scenarios (MCM).

\begin{tabular}{ccccccc}
\hline & \multicolumn{2}{c}{ Upstream } & \multicolumn{2}{c}{$\begin{array}{c}\text { Koka Reservoir } \\
\text { Storage Volume }\end{array}$} & \multicolumn{2}{c}{$\begin{array}{c}\text { Awash-Ziway } \\
\text { Diverted Volume }\end{array}$} \\
\cline { 2 - 7 } & Bemand Delivery & Diversion & Base & Diversion & Base & Diversion \\
\hline Jan & 30.0 & 29.3 & 724.3 & 722.1 & 0.0 & 0.0 \\
Feb & 25.7 & 25.7 & 657.7 & 657.1 & 0.0 & 0.0 \\
Mar & 14.7 & 14.7 & 614.5 & 613.9 & 0.0 & 0.0 \\
Apr & 7.9 & 7.8 & 600.0 & 599.5 & 0.0 & 0.0 \\
May & 2.2 & 2.2 & 581.0 & 580.5 & 0.0 & 0.0 \\
Jun & 3.4 & 3.4 & 571.4 & 559.4 & 0.0 & 18.2 \\
Jul & 5.9 & 5.9 & 811.6 & 714.5 & 0.4 & 88.0 \\
Aug & 5.6 & 5.6 & 1038.0 & 1006.7 & 7.0 & 191.5 \\
Sep & 7.7 & 7.7 & 1038.0 & 1038.0 & 3.4 & 3.4 \\
Oct & 21.5 & 21.5 & 965.1 & 962.5 & 0.00 & 0.00 \\
Nov & 26.2 & 26.2 & 887.1 & 884.6 & 0.00 & 0.00 \\
Dec & 27.5 & 27.5 & 798.8 & 796.4 & 0.00 & 0.00 \\
Annual & 178.3 & 178.3 & & & 10.8 & 301.0 \\
\hline
\end{tabular}

\section{Discussion}

The four lakes in the CRVL sub-basin play a significant role in the environmental and economic well-being of the sub-basin as well as for the ecosystem since they are shelter for many endemic and migrant birds [19]. They were a single large lake at a higher elevation, which overflowed to the Awash River in the late Pleistocene or early Holocene period [20]. In almost the same manner, they are interconnected through the surface and sub-surface water flow system today. Lake Ziway and Lake Langano interconnect with Lake Abijata through Bulbula and Horakalo Rivers, respectively. Both Lake Abijata and Shalla are terminal lakes (without surface water outflow) but they are linked with each other through a sub-surface water flow system. The lakes are highly climate-sensitive by nature, where the fluctuation of rainfall and temperature in the sub-basin area directly reflects on their water level [21] [22]. The increased abstraction of fresh water for irrigation from Lake Ziway and its feeding rivers Meki and Katar, has resulted in rapid surface area shrinkage and reduction in lake level. In particular Lake Abijata, the host lake for the endemic migrant birds, suffers with water scarcity and environmental degradation. On the contrary, the changes of climatic and land use changes the flow conditions of Upper Awash sub basin and recurrent flooding has been recorded for the last decade [23]. Moreover, loss of $40 \%$ of the storage capacity of Koka Reservoir exacerbates flooding in the Upper Awash River to the downstream locations, which have significant sugarcane development. 
With the inter-basin water transfer evaluated in this study, regional imbalances could be reduced and mutual benefits can be gained by way of providing additional water to CRVL and providing flood moderation in the Awash River. The optimal amount of diverted water, $300 \mathrm{mcm}$, could potentially stabilize the environmental degradation of Lake Ziway and Lake Abijata by compensating for development driven abstraction and surface water evaporation respectively [24]. Flood occurrences at the Upper Awash River can be mitigated by diverting surplus water during the rainy season, which was quantified as $18 \mathrm{mcm}, 88 \mathrm{mcm}$ and $192 \mathrm{mcm}$ in months June, July and August respectively under average conditions. Since the proposed diversion canal, to divert water from Awash River to Lake Ziway through Meki River has the capacity to pass the historical maximum flow $(137 \mathrm{cms})$ at the diversion location; it has a capacity to divert more water at the time of high flood conditions.

\section{Conclusion}

Population growth, environmental constraints and climate change can adversely affect water supply systems' ability to keep up with demand. The end goal of this hydrological analysis was to quantify the amount of surplus water that can be transferred from the Upper Awash sub-basin to the CRVL sub basin in order to secure access to adequate water resources for expanding populations and economies, whilst maintaining healthy freshwater ecosystems and the vital services they provide. To achieve this, supply side management through an inter-basin water transfer; which involves moving water from a basin with surplus water resources (donor basin) to a basin suffering from shortage (recipient basin) was modeled in WEAP. Historical data analysis from period 1981-2016 was used to model the donor and recipient basins and indicated that it is possible to divert an average of $301 \mathrm{mcm}$, up to a maximum of $553 \mathrm{mcm}$, of water from Awash River to Meki River. The temporal variation of excess water during the rainy season (June, July and August) was analyzed with varying maximum discharge between $19 \mathrm{cms}$ in June to $137 \mathrm{cms}$ in August. The study also revealed that the storage reservoir in the donor basin, Koka Dam, can be guaranteed full at the end of the rainy season and the supply delivered to upstream water users satisfied before any surplus water is diverted. The study finally showed that, by diverting surplus water which causes flooding in the Awash River corridor, to the existing natural storage, Lake Ziway in the water deficit basin, environmental and economic water deficits can be mitigated.

\section{Conflicts of Interest}

The authors declare no conflicts of interest regarding the publication of this paper.

\section{References}

[1] Meshesha, D.T., Tsunekawa, A. and Tsubo, M. (2012) Continuing Land Degrada- 
tion: Cause-Effect in Ethiopia's Central Rift Valley. Land Degradation and Development, 23, 130-143. https://doi.org/10.1002/ldr.1061

[2] Hulshof, M. (2019) Literature Review Ziway-Shalla Basin in Balance. Final Report, Project Number 180849.

[3] Ayenew, T. (2002) Recent Changes in the Level of Lake Abijata, Central Main Ethiopian Rift. Hydrological Sciences Journal, 47, 493-503. https://doi.org/10.1080/02626660209492949

[4] Gashew, H. (1998) Hydrogeology and Hydrochemistry of Lake Ziway Area and the Surrounding. M.Sc. Thesis, Addis Ababa University, Addis Ababa, 117.

[5] Pascual-Ferrer, J., Pérez-Foguet, A., Codony, J., Raventós, E. and Candela, L. (2014) Assessment of Water Resources Management in the Ethiopian Central Rift Valley: Environmental Conservation and Poverty Reduction. International Journal of Water Resources Development, 30, 572-587. https://doi.org/10.1080/07900627.2013.843410

[6] Raventós Vilalta, E. (2010) Water Resources Management in the Central Rift Valley of Ethiopia. Universitat Politècnica de Catalunya, Barcelona

[7] Graichen, K. (2011) Lake Water Management in Three Ethiopian Rift Valley Watersheds, Chapter 4. Environmental Policy Review 2011, the Environmental Policy Group, Environmental Studies Program, Colby College in Waterville, Maine.

[8] JICA (2012) The Study on Groundwater Resources Assessment in the Rift valley Lakes Basin in Ethiopia. Final Report (Supporting Report), Kokusai Kogyo Co., Ltd., Tokyo.

[9] Mulugeta, D.B., Diekkrüger, B. and Roehrig, J. (2015) Characterization of Water Level Variability of the Main Ethiopian Rift Valley Lakes.

https://www.mdpi.com/journal/hydrology

[10] Lemma, A.H. (2016) Current Ecological Scenario of some Rift Valley Lakes of Ethiopia: A Review. EC Agriculture, 3, 570-580.

[11] FAO (2012) Coping with Water Scarcity. An Action Framework for Agriculture and Food Security. Food and Agriculture Organization of the United Nations, Rome, Italy.

[12] Zhao, Z.Y., Zuo, J. and Zillante, G. (2017) Transformation of Water Resource Management: A Case Study of the South-to-North Water Diversion Project. Journal of Cleaner Production, 163, 136-145. https://doi.org/10.1016/j.jclepro.2015.08.066

[13] Shiklomanov, I.A. (1999) World Water Resources: Modern Assessment and Outlook for the 21stCentury. St Petersburg, Federal Service of Russia for Hydrometeorology and Environment Monitoring, State Hydrological Institute UNCSD.

[14] Gurara, M., Bekele, A. and Selamawit, G. (2020) Hydrological Data Processing and Management System: Case Study for Upper Awash Sub-Basin Flow Data Processing for Koka Reservoir Management. Vol. 9.

[15] Gedefaw, M., Wang, H., Yan, D., Qin, T., Wang, K., Girma, A., Batsuren, D. and Abiyu, A. (2019) Water Resources Allocation Systems under Irrigation Expansion and Climate Change Scenario in Awash River Basin of Ethiopia. Water, 11, 1966. https://doi.org/10.3390/w11101966

[16] Wishart, M.J. and Emenanjo, I. (2017) Lesotho WEAP Manual. The World Bank, $1-43$.

[17] SEI (2015) WEAP User Guide. Stockholm Environment Institute (SEI).

[18] Funk, C., Verdin, A., Michaelsen, J., Peterson, P., Pederos, D. and Husak, G. (2015) A Global Satellite Assisted Precipitation Climatology. Earth Systems Science Data 
Discussion, 8, 401-425. https://doi.org/10.5194/essdd-8-401-2015

[19] Israel, P.M. and Timar, P.M. (2018) Wetland Ecosystems in Ethiopia and Their Implications in Ecotourism and Biodiversity Conservation. Journal of Ecology and the Natural Environment, 10, 80-96.

[20] Grove, A.T., Alayne Street, F. and Goudie, A.S. (1975) Former Lake Levels and Climatic Change in the Rift Valley of Southern Ethiopia. The Geographical Journal, 141, 177-194. https://www.jstor.org/stable/1797205 https://doi.org/10.2307/1797205

[21] Street, F.A. (1979) Late Quaternary Lakes in the Ziway-Shala Basin, Southern Ethiopia. Ph.D. Thesis, University of Cambridge, Cambridge, UK, 457.

[22] Chernet, T. (1982) Hydrogeologic Map of the Lakes Region (with Memo). Ethiopian Institute of Geological Surveys, Addis Ababa, Ethiopia.

[23] Woldegebrael, S.M., Berhanu, B., Zaitchik, B. and Melesse, A.M. (2020) Rainfall and Flood Event Interrelationship-A Case Study of Awash and Omo-Gibe Basins, Ethiopia. International Journal of Scientific \& Engineering Research, 11, 332-343.

[24] GIRDC, BDA and IDH Water Resources Potential and Demand Study in Ziway Shalla Sub-Basin: Annex A. Surface Water Resource Potential, Draft Final Report, Unpublished. 